\title{
Effect of Supplementary Cementitious Materials on the Compressive Strength and Durability of Short-Term Cured Concrete
}

H. Toutanji

University of Alabama - Huntsville

Norbert Delatte

Cleveland State University, n.delatte@csuohio.edu

S. Aggoun

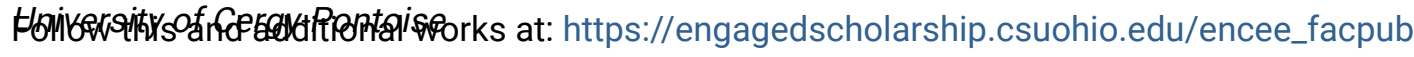

Davabf the Civil Engineering Commons

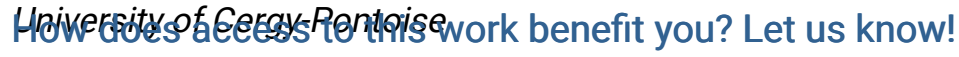

R.ublishorits Statement

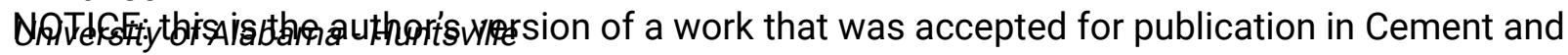

Concrete Research. Changes resulting from the publishing process, such as peer review, editing, corrections, structural formatting, and other quality control mechanisms may not be reflected in this document. Changes may have been made to this work since it was submitted for publication. A definitive version was subsequently published in Cement and Concrete Research, 34, 2, (02-01-2004); 10.1016/j.cemconres.2003.08.017

\section{Original Citation}

Toutanji, H., Delatte, N., Aggoun, S., Duval, R., and Danson, A. (2004). "Effect of supplementary cementitious materials on the compressive strength and durability of short-term cured concrete." Cem.Concr.Res., 34(2), 311-319.

This Article is brought to you for free and open access by the Civil and Environmental Engineering at EngagedScholarship@CSU. It has been accepted for inclusion in Civil and Environmental Engineering Faculty Publications by an authorized administrator of EngagedScholarship@CSU. For more information, please contact library.es@csuohio.edu. 


\title{
Effect of supplementary cementitious materials on the compressive strength and durability of short-term cured concrete
}

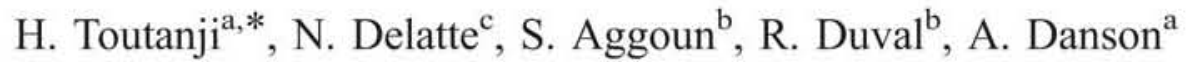 \\ a Department of Civil and Environmental Engineering, University of Alabama in Huntsville, Huntsville, AL 35899, USA \\ ${ }^{\mathrm{b}}$ University of Cergy-Pontoise, IUP Génie Civil et Infrastructures, 95031 CERGY-PONTOISE Cedex, Cergy-Pontoise, France \\ ${ }^{\mathrm{c} D e p a r t m e n t}$ of Civil and Environmental Engineering, University of Alabama at Birmingham, Birmingham, AL 35294, USA
}

\section{Introduction}

Issues concerning the durability of bridge decks have been of great concern to civil engineers and highway agencies. Many have proposed the use of supplementary cementitious materials to alleviate these concerns. It is important to establish how these materials can improve the durability of concrete. Research concerning the use of mineral admixtures to augment the properties of concrete has been going on for many years. Recently, the use of mineral admixtures has dramatically increased due to an increase in environmental awareness. Higher early strength can be found in some modern cements due to more $\mathrm{Ca}(\mathrm{OH})_{2}$ formation, but this may adversely effect the durability and cost of concrete [1]. Since many mineral admixtures are by-products of other industries, these waste by-products can be used to reduce the amount of cement required, thus, in some cases reducing the cost of the concrete. Mineral admixtures such as silica fume, fly ash, and ground granulated blast furnace slag should be studied in order to understand their ability to enhance the properties of concrete. Each of these supplementary materials possesses different properties and reacts differently in the presence of water.

Silica fume possesses a bulk density ranging from 200 to $300 \mathrm{~kg} / \mathrm{m}^{3}$ and a specific gravity of approximately 2.20 . It was first utilized in the 1970s as an additive in the concrete used to construct of the Fiskaa Smelter [2] in Norway. The addition of silica fume increases the early strength of concrete while reducing its permeability [3]. Silica fume serves a dual role as a filler and pozzolan [2]. Due to its small particle size, it can enter the spaces that exist between the particles of cement to improve packing. It contributes to the formation $\mathrm{C}-\mathrm{S}-\mathrm{H}$. Potentially, silica 
fume could replace small portions of cement due to its high reactivity with calcium hydroxide produces during the hydration of Portland cement. It may reduce bleeding and porosity as a result of its fineness. However, the properties of silica fume are enhanced by the presence of superplasticizers in the mix. The resistance of silica fume to freeze-thaw cycling is unclear.

Recommendations concerning the use of fly ash in concrete have been made suggesting the use of $40 \%$ or less. Furthermore, if early strength is not an important factor, fly ash as high as $60 \%$ can be used [4]. Unlike silica fume, fly ash mixes require longer periods of time to develop strength. It is shown that at 91 days, the strength of mixes incorporating fly ash outperform specimens made without additives [5]. Compared to silica fume, fly ash mixes using excessive amounts of highranged water-reducing (HRWR) agent may cause segregation of different materials, resulting in lower strength. The reduction in porosity of concrete incorporating fly ash can be linked to improvements that occur on the interfacial transition zones between the cement matrix and the aggregate. The reaction of $\mathrm{CH}$ and fly ash forms $\mathrm{CSH}$ gel, which results in increased compressive strengths. On the downside, fly ash tends to have a low reaction rate when used as an admixture in Portland cement mixes. At 28 days, the degree of fly ash reaction rate is slightly more than $10 \%$ [6-9]. Furthermore, only $20 \%$ of the fly ash reacts after 90 days. One explanation for the low activity of fly ash at room temperature is that the $\mathrm{pH}$ of the solution 13 does not meet the requirements of fly ash, 13.3 [10].

Slag forms as a waste product from both ferrous and nonferrous metals industries. High-slag-cements have low strength at early ages. This is due to the slow hydration reaction of slag. Unlike fly ash, slag's reactivity is dependent more on temperature $[11,12]$. Two processes govern slag's reaction rate during the initial period of hydration. The first is the nucleation and the growth rate of hydration phases. These compounds are then transformed into CSH gel. The second is the phase boundary interactions or the interactions that occur between the old compounds and the newly formed compounds. It has also been found that the initial rate of hydration is dependent on the initial lime content. This can be observed in the sharp decreases in the free lime contents that occur in high-lime slag mixes during the first day of hydration [13]. These compounds or hydrates are generally more gel-like in structure than the products of Portland cement. These hydrates add to the density of the cement paste. Also the hydration of slag, in the presence of Portland cement, depends greatly upon the breakdown and dissolution of glassy slag structures by hydroxide anions $(\mathrm{OH})^{-}$. This ion release occurs during the hydration of cement. ASTM C989 recommends the use of the slag activity index as a basic criterion for evaluating the value of cementitious materials $[11,14,15]$. Research show that high contents of slag, as high as $65 \%$, after 28 days of hydration provide the lowest overall rate of degradation and the best overall durability of concrete exposed to magnesium brine [16].

Concrete that has the ability to resist the destructive forces imposed upon it, by environmental constraints and without requiring excessive maintenance, is termed durable concrete. Factors such as freeze-thaw and wet-dry cycling can cause deterioration of concrete in a relatively short period of time. Therefore, concrete durability is directly correlated to its state of deterioration. The water present in concrete, exposed to freezing conditions, undergoes an expansion process. This is primarily due to the $9 \%$ expansion of the water in the concrete [17]. As the water in the moist concrete freezes, it produces osmotic and hydraulic pressures in the cement paste and the aggregate. As these pressures increase, micro-cracks begin to form and finally rupture. Rupture occurs as the pressure exceeds the tensile strength of the paste or aggregate. Resistance to freezing and thawing depends on many factors: permeability, degree of saturation, amount of freezable water, and rate of freezing. Freeze-thaw resistance can be increased with the selection of good quality aggregate, the low water/cement ratio, the right amount of cement content, and the proper curing conditions. Wet-dry cycling conditions can contribute to the deterioration of concrete. This primarily occurs with brackish waters having high salinity. Over time, the salt incorporates into the mix through the voids that naturally occur in the concrete. The salt then attacks the bond in the concrete, thereby causing the mix to develop cracks and eventually fail. This can also be detrimental to a concrete mix containing steel, since steel is susceptible to corrosion.

The most important design parameter for concrete structures is compressive strength. This critical parameter drives the design process and can influence the cost of a project. Through the use of certain mineral admixtures, the cost of concrete can be reduced. These admixtures also enhance the properties of mortar or concrete. In some cases, a boost in early strength becomes apparent, while in others, an increase in late strength occurs. Also, from an environmental standpoint, the use of these materials is paramount, since the production of cement creates substantial amounts of pollution. This research intended to expand the knowledge concerning the proper use of these admixtures in concrete cured for a short period, in addition to determining the combined effects of these materials on the properties of concrete.

\section{Experimental procedure}

\subsection{Specimens preparation}

The test specimens were cast from 16 separate batches of concrete: one control, nine mixes containing different 
Table 1

Chemical and physical properties of the supplementary cementitious materials

\begin{tabular}{|c|c|c|c|c|c|}
\hline & \multirow{2}{*}{$\begin{array}{l}\text { Chemical } \\
\text { compound }\end{array}$} & \multicolumn{4}{|c|}{ Percent of total weight } \\
\hline & & $\begin{array}{l}\text { ASTM } \\
\text { Type I } \\
\text { cement }\end{array}$ & $\begin{array}{l}\text { Silica } \\
\text { fume }\end{array}$ & $\begin{array}{l}\text { Fly ash } \\
\text { (Class C) }\end{array}$ & $\begin{array}{l}\text { Slag } \\
\text { (Grade 120) }\end{array}$ \\
\hline \multirow{8}{*}{$\begin{array}{l}\text { Chemical } \\
\text { composition }\end{array}$} & $\mathrm{SiO}_{2}$ & 20.6 & 95.75 & 58.64 & 35.78 \\
\hline & $\mathrm{Al}_{2} \mathrm{O}_{3}$ & 4.0 & 0.35 & 25.94 & 12.31 \\
\hline & $\mathrm{Fe}_{2} \mathrm{O}_{3}$ & 3.1 & 0.21 & 6.55 & 1.02 \\
\hline & $\mathrm{CaO}$ & 62.8 & 0.17 & 2.78 & 43.86 \\
\hline & $\mathrm{MgO}$ & 2.6 & 0.09 & 1.16 & 9.33 \\
\hline & $\mathrm{SO}_{3}$ & 3.1 & 0.42 & 0.40 & 2.71 \\
\hline & $\mathrm{Na}_{2} \mathrm{O}$ & 0.8 & 0.51 & 0.24 & 0.24 \\
\hline & $\mathrm{K}_{2} \mathrm{O}$ & - & 0.16 & 2.46 & 0.42 \\
\hline \multirow[t]{4}{*}{$\begin{array}{l}\text { Physical } \\
\text { properties }\end{array}$} & $\begin{array}{l}\text { specific } \\
\text { gravity }\end{array}$ & 3.15 & 2.25 & 2.62 & 2.99 \\
\hline & $\begin{array}{l}\text { avg. particle } \\
\text { size }(\mu \mathrm{m})\end{array}$ & 0.1 & 0.1 & 1.0 & 35 \\
\hline & $\begin{array}{l}\text { bulk density } \\
\left(\mathrm{kg} / \mathrm{m}^{3}\right)\end{array}$ & - & 224.7 & - & - \\
\hline & $\begin{array}{l}\text { surface area, } \\
\text { Blaine }\left(\mathrm{m}^{2} / \mathrm{kg}\right)\end{array}$ & 388 & - & 400 & 500 \\
\hline
\end{tabular}

percentages of silica fume, slag, and fly ash, and six mixes made of combinations of the cement, silica fume, and fly ash. The chemical compositions and some physical properties of the supplementary cementitious materials are shown in Table 1 . The mix design ratio of the concrete was cementitious materials/sand/gravel/water (1.0:2.1:2.9:0.40 by weight). Type I ASTM cement was used. The fine aggregate consisted of $40 \%$ natural river sand and 60\% manufactured sand. The coarse aggregate consisted of gravel with a maximum size of $12 \mathrm{~mm}$. The amount of superplasticizer added was between $1.5 \%$ and $2.5 \%$ by weight of the cementitious materials. The superplasticizer, manufactured by W.R. Grace, contained $40 \%$ air entrainment. In the combination mixes, the amount of cement was kept constant at $50 \%$ by mass of the cementitious materials. The combination mixes were designated as A, B, C, D, E, and F. The mix proportions of these mixes were as follows: cement/silica fume/fly ash/slag (50\%:10\%:15\%:25\% for Mix A, 50\%:5\%:10\%:35\% for Mix B, 50\%:7.5\%:12.5\%: $30 \%$ for Mix C, 50\%:0\%:10\%:40\% for Mix D, 50\%:0\%,20\%:30\% for Mix E, and 50\%:0\%:25\%:25\% for Mix F). Details of all mixes are shown in Table 2. In each mix, specimens were divided into three groups: control, wet-dry, and freeze-thaw specimens. In each group, beams measuring $3 \times 4 \times 16$ in. and cylinders measuring $4 \times 8$ in. were made. The reported strength values represented the average strength of three specimens. All specimens were moist cured for 14 days before testing or before they were subjected to the environmental conditions. The cylinders and beams were then placed in their respective testing chambers and the required test cycles were run.
The following describes the procedure used for mixing all samples:

- Measure all the mix ingredients in the proportions and make sure that all the metal instruments and tools are moist (mixing drum, trowels, mixing trays, and rods). This ensures that the moisture content is not drastically reduced by the properties of the metallic instruments. In addition, make sure that there is no standing water in mixing drum or pans.

- Place the coarse aggregate into the mixing drum and then add the fine aggregate (natural and manufactured sand). Turn on the mixer and allow it to mix for $1 \mathrm{~min}$.

- Mix the cementitious components (slag, fly ash, silica fume, and Portland cement) together in a container. Stop the mixer and then place the cementitious materials into the mixing drum followed by adding half of the liquid. The liquid is prepared by adding the required superplasticizer to the measured water.

- While the mixing drum is running, pour the liquid deep into the mixer. It is preferable to pour the liquid directly into the mix if possible.

- After 1 min of mixing, add the rest of the liquid and mix for another $5 \mathrm{~min}$.

- Lower the handle of the concrete mixer and pour the contents out into a moistened pan.

The workability and consistency of the concrete mixes were measured using the slump cone test ASTM C143-89a [18]. After the slump test was completed, the specimen molds were oiled and placed on a leveled surface to be filled with the concrete mixture. The specimens were cast in accordance with ASTM C192-88 [19]. Plastic sheets were used to cover the specimens to prevent the water from evaporating. After $24 \mathrm{~h}$, the specimens were striped from

Table 2

Mix proportions

\begin{tabular}{lccccll}
\hline Mix & $\begin{array}{l}\text { Cement } \\
(\%)\end{array}$ & $\begin{array}{l}\text { Silica } \\
\text { Fume } \\
(\%)\end{array}$ & $\begin{array}{l}\text { Slag } \\
(\%)\end{array}$ & $\begin{array}{l}\text { Fly } \\
\text { ash } \\
(\%)\end{array}$ & $\begin{array}{l}\text { Superplasticizer } \\
(\%)\end{array}$ & $\begin{array}{l}\text { Slump } \\
\text { (in.) }\end{array}$ \\
\hline Control & 100 & 0 & 0 & 0 & 2 & 6.5 \\
$8 \%$ SF & 92 & 8 & 0 & 0 & 2 & 3 \\
$10 \%$ SF & 90 & 10 & 0 & 0 & 2.5 & 3 \\
$15 \%$ SF & 85 & 15 & 0 & 0 & 2.5 & 2 \\
$60 \%$ S & 40 & 0 & 60 & 0 & 1.5 & 4.0 \\
$70 \%$ S & 30 & 0 & 70 & 0 & 1.5 & 4.5 \\
$80 \%$ S & 20 & 0 & 80 & 0 & 1.5 & 5.5 \\
$20 \%$ FA & 80 & 0 & 0 & 20 & 1.5 & 5.0 \\
$25 \%$ FA & 75 & 0 & 0 & 25 & 1.5 & 5.5 \\
$30 \%$ FA & 70 & 0 & 0 & 30 & 1.5 & 6 \\
Combined A & 50 & 10 & 25 & 15 & 2.0 & 0 \\
Combined B & 50 & 5 & 35 & 10 & 2.0 & 0.5 \\
Combined C & 50 & 7.5 & 30 & 12.5 & 2.0 & 3 \\
Combined D & 50 & 0 & 40 & 10 & 2.0 & 3 \\
Combined E & 50 & 0 & 30 & 20 & 2.0 & 2.75 \\
Combined F & 50 & 0 & 25 & 25 & 2.0 & 3.5 \\
\hline
\end{tabular}


their respective molds and placed in water to cure for 14 days. Following the casting process, all instruments were cleaned thoroughly including the mixer and prepared for the next mix.

\subsection{Freeze-thaw test (ASTM)}

The standard freeze-thaw test entails subjecting the specimen to 300 cycles of rapid freezing and thawing conditions. The guidelines of the ASTM C666 procedure "Standard Test Method for Resistance of Concrete to Rapid Freezing and Thawing" were used [20]. The freezing and thawing machine consists of a stainless steel cabinet with 18 compartments for $3 \times 4 \times 16$ in. beams. The temperature at the center of the control specimens ranges from 40 to $0{ }^{\circ} \mathrm{F}$. The cabinet contains 3 in. of insulation on all sides and a refrigeration unit mounted on the underframe. Controls and a 7-day temperature recorder can be located at the end of the cabinet. The machine uses several mechanisms to measure the resistance of the concrete specimens to freezing and thawing conditions. Specimens are subjected to freezing and thawing conditions, while surrounded by $1 / 8$-in. layer of water. The specimens undergo a maximum nine cycles of freezing and thawing per $24-\mathrm{h}$ period. Simultaneously, a continuous record of the temperature at the center of the control specimen is plotted on a 7-day recording chart.

After every 25-30 freeze-thaw cycles, the specimens were tested for fundamental transverse frequency according to ASTM C215. The specimens were weighed and measured for average length and cross-sectional dimen- sions. The process continued until either 300 cycles of freezing and thawing were completed or until the dynamic modulus of elasticity fell below $50 \%$. This test is quantitative in nature and highly repeatable.

\subsection{Wet-dry test}

The cylinders were placed in a specially constructed environmental chamber, located in the Materials Lab at the Civil and Environmental Engineering Department of UAH. Cylinders were exposed to 300 cycles of wetting and drying. The wet-dry environmental chamber is schematically shown in Fig. 1. This chamber utilized two pumps and an industrial dryer to cycle the cylinders constantly. This constant cycling was achieved by connecting the pumps and dryer to a series of timers set to activate at specified times. The cylinders were subjected to salt water environments in which there were alternating wet and dry cycles (hot air at $35{ }^{\circ} \mathrm{C}$ average and $90 \%$ humidity). Seawater was simulated using $35 \mathrm{~g}$ of salt $(\mathrm{NaCl})$ in a liter of water. This approximates the content of salt found in the ocean. The duration of the wet cycle was $4 \mathrm{~h}$. The dry cycle was $8 \mathrm{~h}$. Thus, the cylinders were exposed to a total of 150 days of testing. After exposure, the cylinders were tested in compression to determine the strength properties.

The compression test was performed using a 400 kips standard ASTM compression tester, manufactured by Forney. The cylinders were capped with sulfur to ensure that the specimens were axially loaded. The cylinders were placed in the machine ensuring that they were directly

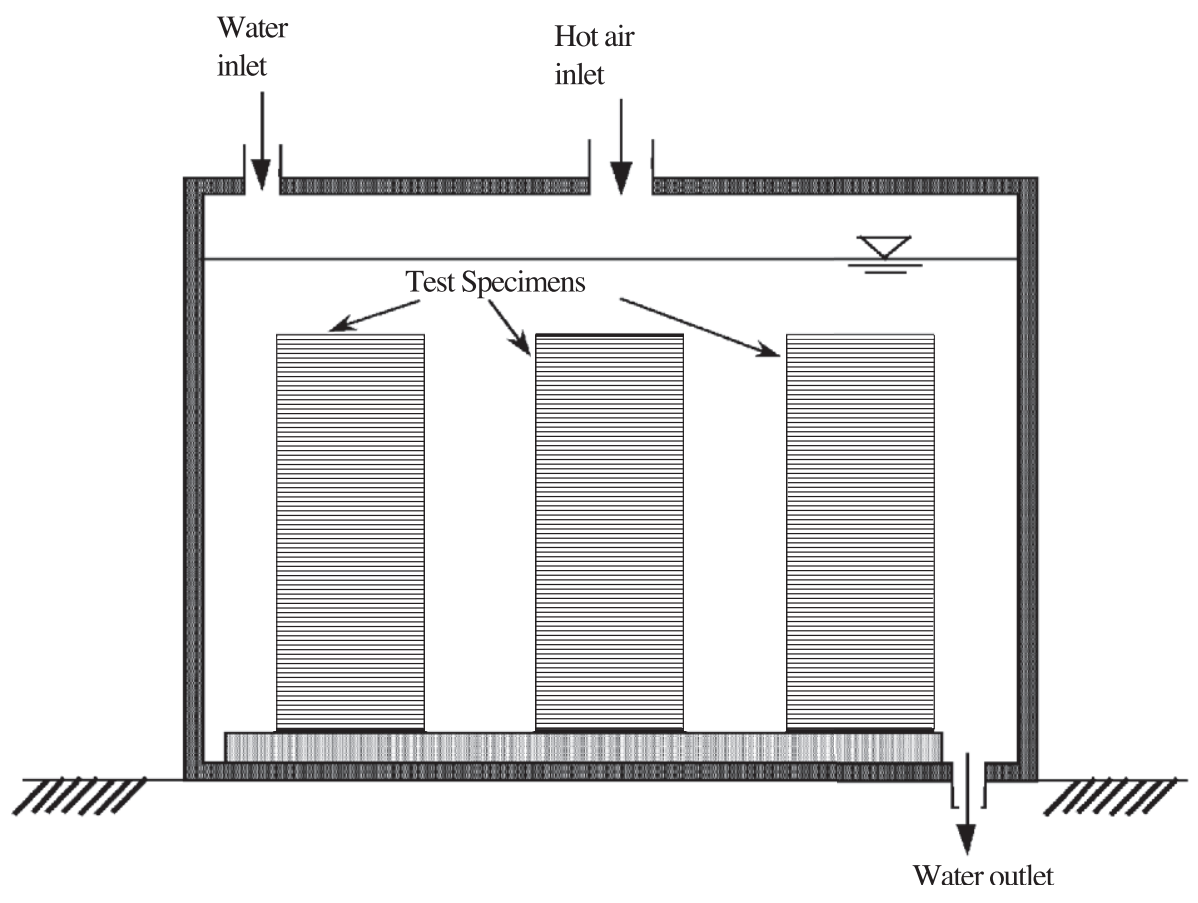

Fig. 1. Schematic of the wet-dry exposure set up. 
under the center of both the top loading cell and the bottom plates. They were then loaded at a rate of $200 \mathrm{psi}$ per minute until failure.

\section{Results}

\subsection{Effect of supplementary cementitious materials on strength}

The addition of silica fume produced the highest increase in strength when compared to the other supplementary cementitious materials (fly ash, slag, and combinations), as shown in Fig. 2. With the addition of $8 \%, 10 \%$, and $15 \%$ of silica fume, the compressive strength increased by $33 \%$, $32 \%$, and $21 \%$, respectively. Addition of $8 \%$ of silica fume by mass is the optimum content that produced the highest increase in strength.

The increase in strength of silica fume concrete could be attributed to the improvement in the bond between the hydrated cement matrix and the aggregate. This is due to the conversion of calcium hydroxide, which tends to form on the surface of aggregate particles to calcium silicate hydrate. However, when the dosage of silica fume increases beyond $10 \%$, the compressive strength starts to decrease. This reduction in strength may be a result of the lack of water in the mix since self-desiccation of the specimens may have taken place. This limits the pozzolanic effect and thereby reduces the strength of the silica fume concrete.
Although, the present work did not study the increase of water demand for silica fume concrete, water amount can increase as much as $30 \%$ depending upon the amount of silica fume in the mixture [21-23].

The addition of slag resulted in a modest increase in strength. Concrete with cementitious materials of $70 \%$ slag seemed to produce the optimum strength as compared to mixes with $60 \%$ and $80 \%$ slag. The addition of $70 \%$ slag resulted in an increase in strength of about $15 \%$ over plain concrete, whereas $60 \%$ and $80 \%$ slag resulted in about $5 \%$ increase.

The addition of fly ash exhibited a reduction in compressive strength. The compressive strength was reduced by as much as $50 \%$ with the addition of $30 \%$ fly ash. This reduction in strength is attributed to the fact that specimens were cured for a short period of time, only 14 days. Because of the slow pozzolanic reactions of fly ash, continuous wet curing and favorable curing temperatures are required for proper development of strength. Some fly ashes require 90 days or more to equal or exceed a 28-day control strength [24]. It should be noted that fly ash has been used in the production of high-strength concrete when it is cured for a long period of time.

The combination of different supplementary materials increased compressive strength (Fig. 2). The combination of $10 \%$ silica fume, $25 \%$ slag, $15 \%$ fly ash, and $50 \%$ cement, Mix A, produced an increase in strength of about $22 \%$ over the control mix. However, a combination of $5 \%$ silica fume, $35 \%$ slag, $10 \%$ fly ash, and $50 \%$ cement (Mix B) produced a

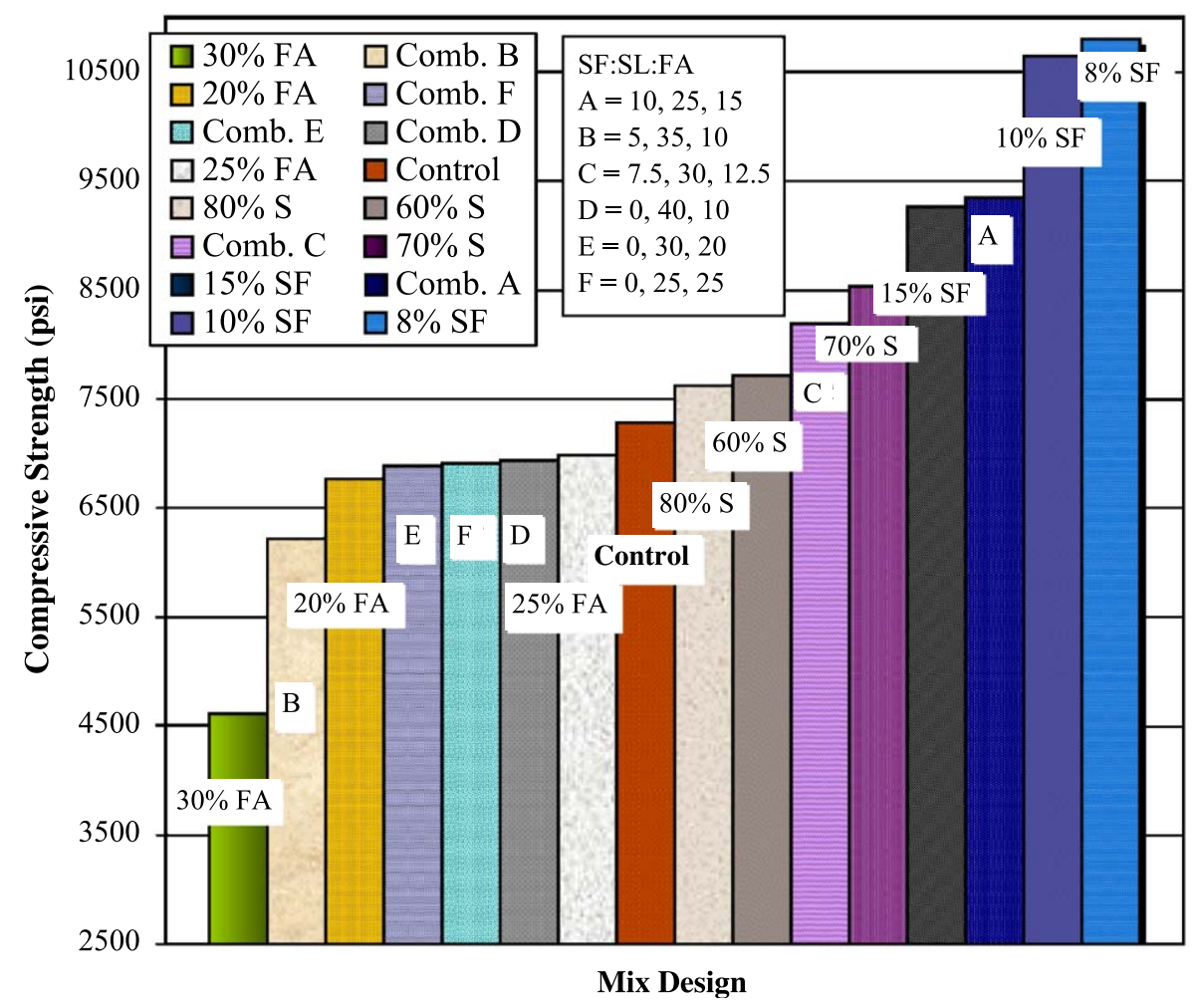

Fig. 2. Compressive strength performance for all mixes. 
reduction in strength of about $15 \%$. The combination of fly ash, slag, and cement (Mixes D, E, and F) did not show significant effects on the strength. There was a reduction of about $5 \%$, which is statistically insignificant.

\subsection{Effect of freeze-thaw conditions on strength}

The freeze and thaw test can be ideal for determining relative durability. It is not intended for quantitative analysis but rather to compare the durability performance of different mixes. However, the extent of service of a particular type of concrete cannot be determined. The durability factor value reflects the required number of freezing and thawing cycles to yield a particular amount of deterioration. The relative dynamic modulus of elasticity of the beams, which is used to calculate the durability factor, is determined by measuring the resonant frequency with a sonometer and can be determined as follows [20]:

$P_{c}=\left(\frac{\eta_{1}^{2}}{\eta_{0}^{2}}\right) 100$

where $P_{c}=$ relative dynamic modulus of elasticity, after $c$ cycles of freezing and thawing (\%). $\eta_{0}=$ fundamental transverse frequency at 0 cycle of freezing and thawing $(\mathrm{Hz})$. $\eta_{1}=$ fundamental transverse frequency after $c$ cycles of freezing and thawing $(\mathrm{Hz})$.

The fundamental transverse frequency was determined in accordance with ASTM C215 "Standard Test Method for
Fundamental Transverse, Longitudinal and Torsional Resonant Frequencies of Concrete Specimens" [25]. The durability factor was calculated as follows:

$\mathrm{DF}=\frac{P_{N} N}{M}$

where $\mathrm{DF}=$ durability factor of the test specimen. $P_{N}=$ relative dynamic modulus of elasticity at $N$ cycles (\%). $N=$ number of cycles at which $P_{N}$ reaches the specified minimum value for discontinuing the test or the specified number of cycles at which the exposure is to be terminated, whichever is less. $M=$ specified number of cycles at which the exposure is to be terminated.

Fig. 3 represents a qualitative estimate of the durability performance of all beams, while Fig. 4 represents the graphs used to determine the durability factors. The durability factor is found by determining the number of cycles $(N)$ at which the relative dynamic modulus of elasticity reached $50 \%\left(P_{N}\right)$. By substituting these values into Eq. (2) and dividing the result by the total number of cycles $(M)$, the resulting values of the durability factor are determined. The relative dynamic modulus of elasticity can be plotted by computing the values of the fundamental transverse frequency found at an initial number of cycles $\left(\eta_{0}\right)$ and at some specified number of cycles $\left(\eta_{\mathrm{c}}\right)$, then the results are substituted into Eq. (1) to obtain the resulting relative dynamic modulus of elasticity.

Results showed that the control samples (COL) possessed higher resistance to freeze-thaw exposure than

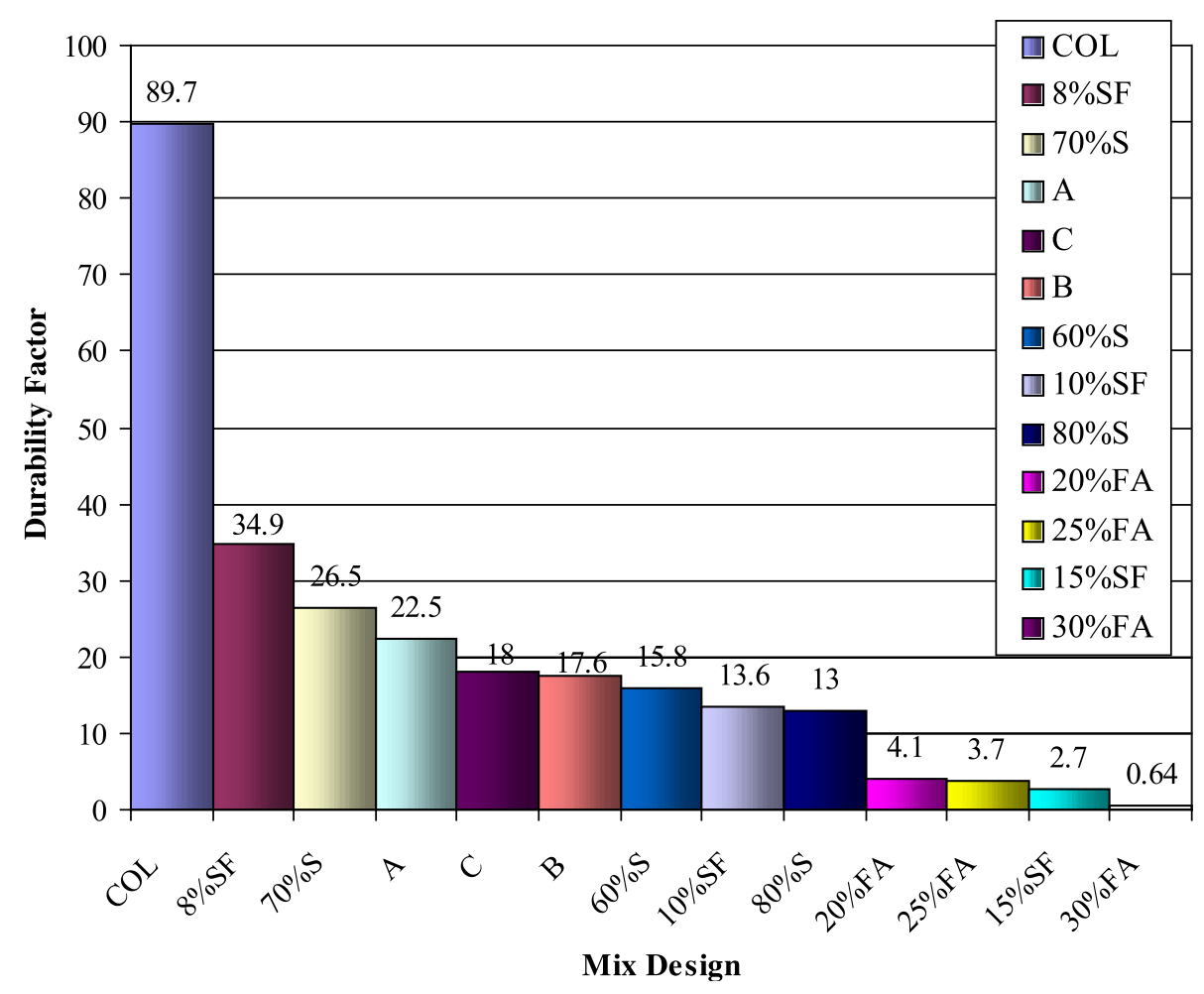

Fig. 3. Durability factor for control and mixes with supplementary cementitious materials. 


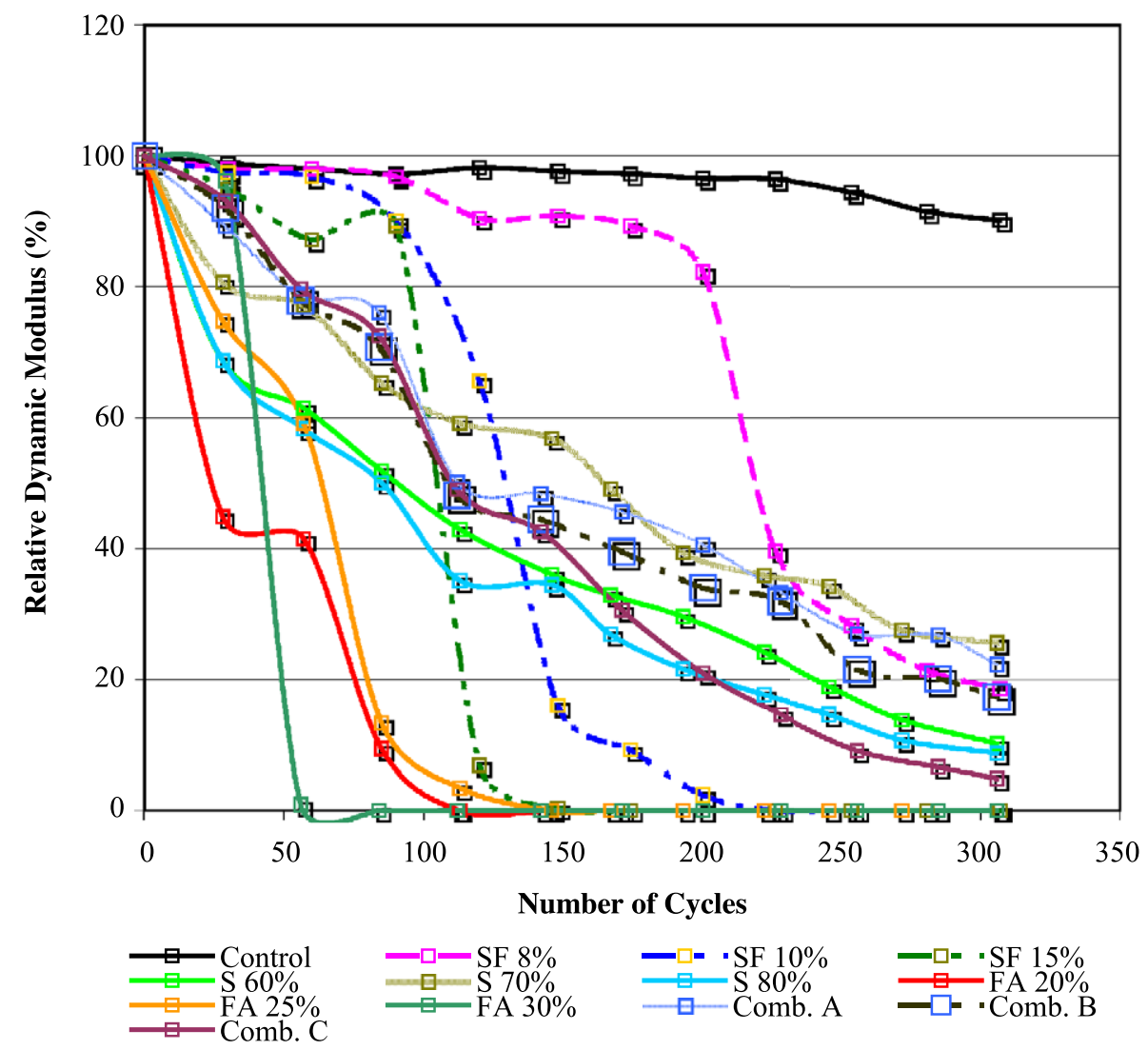

Fig. 4. Relative dynamic modulus of elasticity of all mixes.

mixes with supplementary cementitious materials. The closest in durability performance to the control specimens was the mix that contained $8 \%$ silica fume. However, increasing content of silica fume beyond $8 \%$ seemed to drastically decrease the durability performance. Thus, the durability of concrete containing silica fume is inversely proportional to the amount added. Concrete containing $8 \%$ silica fume exhibited a 2 -fold increase in durability performance over specimens containing $10 \%$ and almost a 13 fold increase over those with $15 \%$. Specimens with slag performed better than those with fly ash. Results showed no correlation between the contents of slag and the durability factor. Other studies have shown that mixes containing higher than $60 \%$ slag may have a higher frost resistance [26].

It appears that the greater the amount of fly ash, the lower the resistance to freeze and thaw exposure. The difference in durability performance between the mix containing $20 \%$ fly ash and $25 \%$ fly ash is small; however, the difference between the mix containing $25 \%$ fly ash and $30 \%$ fly ash is significant. It is crucial to note that these mixes were cured for only 14 days before exposure. The results may have been quite different if the specimens were cured for a longer period of time.

The second highest average durability factors occurred in the combination mixes. On the average, Mixes A, B, and $\mathrm{C}$ performed better than most mixes containing a single admixture. This may be attributed to the fact that the interaction of silica fume, slag, and fly ash resulted in a more stabilized mix. Finding an optimum mix ratio that produces the best durability performance would require further research. In addition, more work should be done to fully understand the reactions and interactions that occur between these various admixtures.

\subsection{Effect of wet-dry exposure on strength}

The compressive strength of plain concrete specimens decreased due to wet-dry cycling using salt water (Fig. 5). The compressive strength was reduced by as much as $13 \%$ due to this exposure. Test results show that by increasing silica fume content, the durability resistance to wet and dry seemed to increase compared to the control specimens (specimens without exposure). The compressive strength of specimens containing $8 \%$ silica fume was reduced by as much as $10 \%$; however, this reduction was seemingly reversed in specimens with silica fume contents greater than $8 \%$. A moderate increase in strength of about $2 \%$ and $6 \%$ was exhibited in specimens with $10 \%$ and $15 \%$ silica fume, respectively.

Mixes with fly ash and slag showed significant increase in strength due to wet-dry exposure. There was a positive 


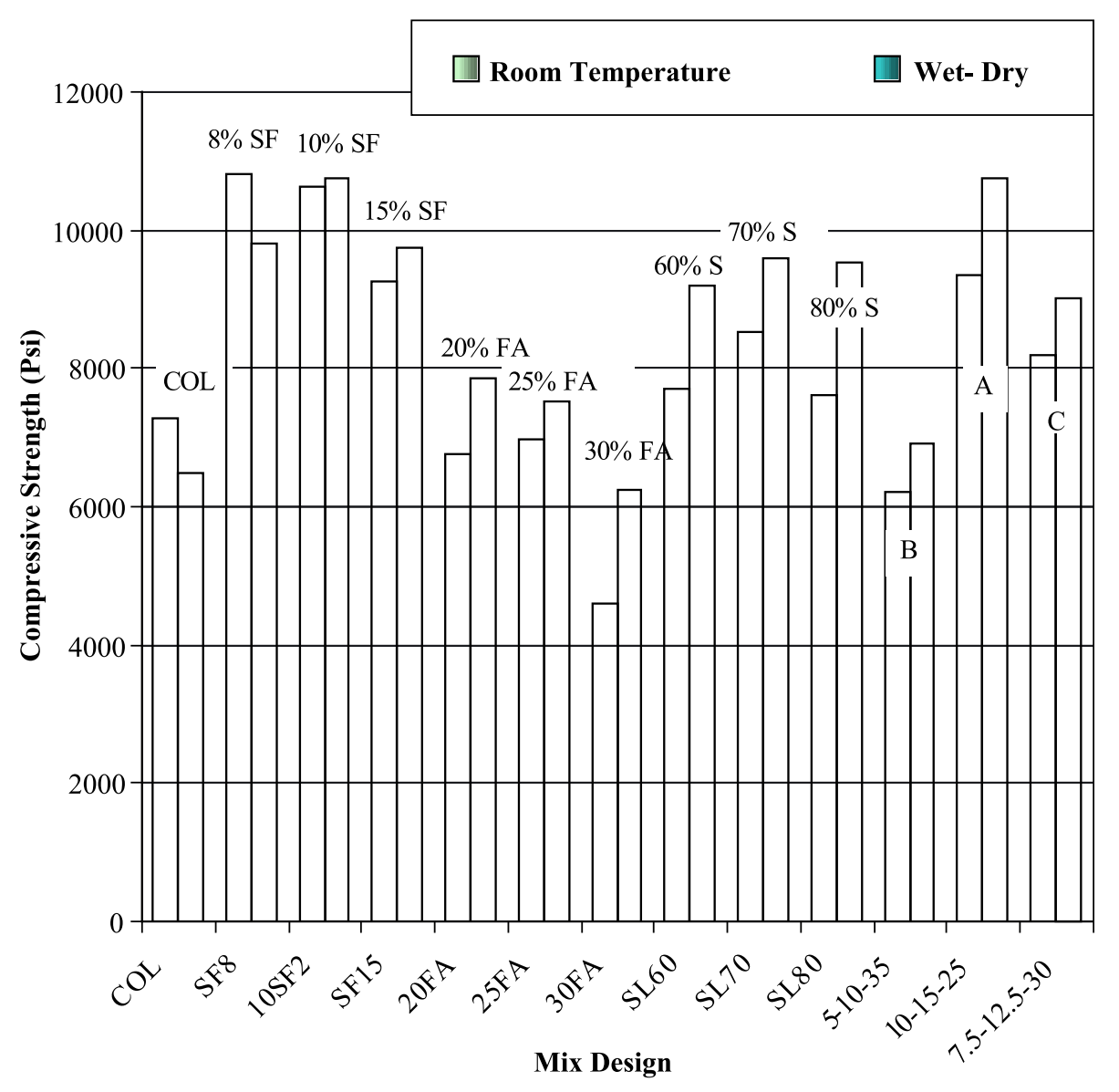

Fig. 5. Compressive strength data for both room temperature and wet-dry conditions.

correlation between the increase in strength and the contents of fly ash and slag in the concrete mixes. For specimens containing $20 \%$ fly ash, the increase in strength was about $16 \%$, whereas specimens with $30 \%$ fly ash experienced an increase in strength of over $30 \%$. For specimens containing $60 \%$ slag, the increase in strength due to wet-dry exposure was about $18 \%$, whereas specimens with $80 \%$ experienced an increase of about $25 \%$. Specimens with different combinations of silica fume, fly ash, and slag also showed increases in strength. Specimens with the largest amount of fly ash, Mix A (10\% silica fume, 15\% fly ash, and 25\% slag), showed the largest increase in strength, about $15 \%$ as shown in Fig. 5.

The reason for this significant increase in strength of specimens containing fly ash and slag is that wet and dry exposure provided these specimens, which contain pozzolanic materials, a longer curing time. Pozzolanic materials require a longer curing time than control specimens, more time to cure and to develop strength. It is hard to quantify the effect of salt water on strength; however, it is clear that the long-term exposure, the frequent wet exposure, and the high drying temperature contributed to the development of strength of these specimens. This explains why slag has been used in seawater environments for many years, typically for the construction of onshore and offshore rigs [26].

\section{Conclusions}

This research focused on studying the effects of different supplementary cementitious materials on strength and durability of concrete cured for a short period of time ( 2 weeks only).

The optimum compressive strength was achieved by adding $8 \%$ SF. However, as the silica fume content increased beyond $10 \%$, the compressive strength decreased. Mixes containing slag experienced a moderate increase in compressive strength. The optimum compressive strength for slag mixes was obtained by replacing $70 \%$ of the cement with slag. As the amount of cement replaced by fly ash increased, the compressive strength decreased. Mix A, with a combination of $10 \%$ silica fume, $25 \%$ slag, and $15 \%$ fly ash, showed the highest increase in strength.

The freeze-thaw durability of the control beams was much better than the rest of the beams. The beams containing fly ash performed quite poorly. However, mixes containing slag and those with combination performed consistently well when exposed to freeze and thaw conditions and when compared with mixes with fly ash.

The compressive strength of the control specimens decreased due to wet and dry exposure. The silica fume cylinders exhibited an increase in strength when its content 
exceeded $8 \%$. More significant increases were observed in the fly ash and slag cylinders over the control specimens. This was due to the fact that slag and fly ash cylinders require a longer curing period. It was clear that long-term exposure of frequent wet and dry cycles contributed to the development of strength of these specimens. This was especially true for the combination mixes, which showed a substantial increase in strength.

It is very important to note that this study conducted on specimens cured for a short period of time; the results may have been completely different if the curing period was much longer. This study and results from others indicate that in order to fully benefit from the addition of these supplementary cementitious materials to concrete, a long curing period is necessary.

\section{Acknowledgements}

The authors would like to acknowledge the financial support of the University Transportation Center for Alabama Grant No. DTRS98-G-0028. The authors are grateful to Dr. Daniel Turner, the Director of UTCA, for providing an extension to complete this work. The support of the University of Cergy-Pontoise, France, is also acknowledged.

\section{References}

[1] W.W.J. Chan, C.M.L. Wu, Durability of concrete with high cement replacement, Cem. Concr. Res. 30 (6) (2000) 865-879.

[2] B.B. Sabir, Mechanical properties and frost resistance of silica fume concrete, Cem. Concr. Composites 19 (4) (1997) 285-294.

[3] R. Duval, E.H. Kadri, Influence of silica fume on the workability and compressive strength of high-performance concretes, Cem. Concr. Res. 28 (4) (1998) 533-547.

[4] T.R. Naik, B.W. Ramme, High-strength concrete containing large quantities of fly ash, ACI Mater. J. 86 (2) (1989) 111-116.

[5] W.S. Langely, G.G. Carette, V.M. Malholtra, High fly ash structural concrete, ACI Mater. J. 86 (5) (1989) 507-513.

[6] C.S. Poon, L. Lam, Y.L. Wong, A study on high-strength concrete prepared with large volumes of low calcium fly ash, Cem. Concr. Res. 30 (3) (2000) 447-455.

[7] L. Lam, Y.L. Wong, C.S. Poon, Degree of hydration and gel/space ratio of high-volume fly ash/cement systems, Cem. Concr. Res. 30 (5) (2000) 747-756.

[8] Y. Chen, D. Li, J. Shen, J. Su, X. Wu, The influence of alkalinity on activation and microstructure of fly ash, Cem. Concr. Res. 30 (6) (2000) $881-886$.

[9] X. Fu, W. Hou, C. Yang, D. Li, X. Wu, Studies on high-strength slag and fly ash compound cement, Cem. Concr. Res. 30 (8) (2000) $1239-1243$.

[10] M.K. Gopalan, Nucleation and pozzolanic factors in strength development of class F fly ash concrete, ACI Mats. J. 90 (2) (1993) $117-120$.

[11] T. Miura, I. Iwaki, Strength development of concrete incorporating high levels of ground granulated blast-furnace slag at low temperatures, ACI Mater. J. 97 (1) (2000) 66-70.

[12] V. Sivasundaram, V.M. Malhotra, Properties of concrete incorporating low quantity of cement and high volumes of ground granulated slag, ACI Mater. J. 89 (6) (1992) 554-563.

[13] N.Y. Mostafa, S.A. El-Hemaly, E.I. Al-Wakeel, S.A. El-Korashy, P.W. Brown, Hydraulic activity of water-cooled slag and air-cooled slag at different temperatures, Cem. Concr. Res. 31 (3) (2001) 475-484.

[14] ACI Committee 226, Granulated blast-furnace slag as a concrete constituent, ACI Mater. J. 84 (4) (1987) 327-342.

[15] E. Douglass, A. Bilodeau, V.M. Malholtra, Properties and durability of alkali-activated slag concrete, ACI Mater. J. 89 (5) (1992) 509-516.

[16] P. Tumidajski, G.W. Chan, Durability of high performance concrete in magnesium brine, Cem. Concr. Res. 26 (4) (1996) 557-565.

[17] A.M. Neville, J.J. Brook, Concrete Technology, Wiley, New York, 1987.

[18] ASTM Designation C143-89a, Standard Test Method for Slump of Hydraulic Cement Concrete, 1994.

[19] ASTM Designation C192-88, Standard Practice for Making and Curing Concrete Test Specimens in the Laboratory, 1994.

[20] ASTM Designation C666-97, Standard Test Method for Resistance to Rapid Freezing and Thawing, 1994.

[21] H. Toutanji, T. El-Korchi, The influence of silica fume on the compressive strength of cement paste and mortar, Cem. Concr. Res. 25 (7) (1995) 1591-1602.

[22] A. Maher, D. Darwin, Microscopic finite element model of concrete, Proc., First Int. Conf. on Mathematical Modeling, University of Missouri-Rolla, St. Louis, V. III, 1977.

[23] ACI Committee 226, Silica fume in concrete, ACI Mater. J. 84 (2) (1987) $158-166$.

[24] S. Kosmatka, W. Panarese, Design and Control of Concrete Mixtures, 13th ed., Portland Cement Association, Skokie, IL, 2000.

[25] ASTM Designation C215-97, Standard Test Method for Fundamental Transverse, Longitudinal and Torsional Resonant Frequencies of Concrete Specimens, 1994.

[26] H.M. Ludwig, J. Stark, Freeze-thaw and freeze-deicing salt resistance of concretes containing cement rich in granulated blast furnace slag, ACI Mater. J. 94 (1) (1997) 47-55. 